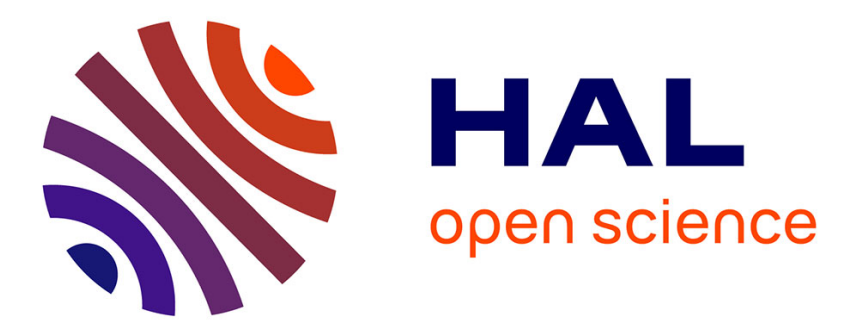

\title{
Design and Implementation of a Neuro-Fuzzy System for Longitudinal Control of Autonomous Vehicles
}

\author{
Joshué Pérez Rastelli, Agustin Gajate, Vicente Milanés, Enrique Onieva, \\ Matilde Santos
}

\section{- To cite this version:}

Joshué Pérez Rastelli, Agustin Gajate, Vicente Milanés, Enrique Onieva, Matilde Santos. Design and Implementation of a Neuro-Fuzzy System for Longitudinal Control of Autonomous Vehicles. Proc. IEEE World Congress on Computational Intelligence WCCI, Jul 2010, Barcelona, Spain. hal00738038

\section{HAL Id: hal-00738038 \\ https://hal.inria.fr/hal-00738038}

Submitted on 3 Oct 2012

HAL is a multi-disciplinary open access archive for the deposit and dissemination of scientific research documents, whether they are published or not. The documents may come from teaching and research institutions in France or abroad, or from public or private research centers.
L'archive ouverte pluridisciplinaire HAL, est destinée au dépôt et à la diffusion de documents scientifiques de niveau recherche, publiés ou non, émanant des établissements d'enseignement et de recherche français ou étrangers, des laboratoires publics ou privés. 


\title{
Design and Implementation of a Neuro-Fuzzy System for Longitudinal Control of Autonomous Vehicles
}

\author{
Joshué Pérez, Agustín Gajate, Vicente Milanés, Enrique Onieva, and Matilde Santos
}

\begin{abstract}
The control of nonlinear systems has been putting especial attention in the use of Artificial Intelligent techniques, where fuzzy logic presents one of the best alternatives due to the exploit of human knowledge. However, several fuzzy logic real-world applications use manual tuning (human expertise) to adjust control systems. On the other hand, in the Intelligent Transport Systems (ITS) field, the longitudinal control (throttle and brake management) is an important topic because external perturbations can generate uncomfortable accelerations as well as unnecessary fuel consumption. In this work, we utilize a neuro-fuzzy system to use human driving knowledge to tune and adjust the input-output parameters of a fuzzy ifthen system. The neuro-fuzzy system considered in this work is ANFIS (Adaptive-Network-based Fuzzy Inference System). Results show several improvements in the control system adjusted by neuro-fuzzy techniques in comparison to the previous manual tuned controller, mainly in comfort and efficient use of actuators.
\end{abstract}

\section{INTRODUCTION}

$\mathrm{C}$ RUISE Control (CC), emergency stop and velocity tracking control are the more common longitudinal control applications, which have been extensively studied in the fields of mobile robots and Intelligent Transportation Systems (ITS) [1]. Indeed, in commercial vehicles, it is progressively implementing safer and more comfortable control for drivers, acting on throttle and brake [2].

Some solutions for controlling the longitudinal actuators have been based on complex models of the autonomous longitudinal system [3]. However, other authors have demonstrated that fuzzy logic offers a good way to model and control complex system, like vehicle's actuators [4].

In 1965, Zadeh defined the fuzzy logic sets of a fuzzy system [5]. Then Tagaki and Sugeno proved this kind of system (using trapezoidal input, if-then rules and singleton consequents) can be applied in modelling and control of mobile robots [4], [6].

The main advantage of a fuzzy controller is that it is not necessary an exact mathematical model of the system to be controlled. Moreover, this controller can emulate the

This work was supported in part by Plan Nacional, Spain, under Project TRANSITO under TRA2008-06602-C03-01, by the Comision Interministerial de Ciencia y Tecnología, Spain, under Project GUIADE (Spain Ministerio de Fomento T9/08).

Joshue Perez (Corresponding author), Agustin Gajate, Vicente Milanés, and Enrique Onieva are with the Instituto de Automática Industrial, CSIC, Arganda del Rey, Madrid, Spain; Email: \{jperez, agajate, vmilanes, onieva\}@iai.csic.es

M. Santos is with the Department of Computer Architecture and Automatic Control, Facultad de Informatica, Universidad Complutense de Madrid, 28040-Madrid, Spain (e-mail: msantos@dacya.ucm.es). behaviour from expert drivers due to knowledge base, using the human experience, and if-then rules.

However, there are some basic aspects in the if-then systems that require special attention. The main aspect is that there aren't standard methods for transforming human knowledge or experience into the rule base and database of a fuzzy system. Moreover, there is a need of automatic and effective methods for tuning the membership functions (MF), rule base and output parameters of the fuzzy systems [7].

Neuro-Fuzzy Systems (NFS) appear in this context merging Artificial Neural Networks (ANN) and Fuzzy Inference System (FIS). Neuro-Fuzzy systems combine the semantic transparency of rule-based fuzzy systems with the learning capability of neural networks. Therefore, NFS are capable of representing systems by means of ifthen rules represented in a network structure, which learning algorithms from the area of artificial neural networks can be applied [8].

Nowadays, several approaches use neuro-fuzzy systems to control nonlinear systems or to adjust controllers [9]. Most of them use the pioneering neuro-fuzzy system, Adaptive Neuro Fuzzy Inference System (ANFIS) [10] because of its simplicity and its computationally efficient procedure [8].

In ITS, neuro-fuzzy systems had been used for modelling traffic flow behaviour, using a specific class of neuro-fuzzy system known as the Pseudo Outer-Product Fuzzy-Neural Network, with Truth-Value-Restriction method (POPFNN-TVR) [11].

In recent years, some applications with vehicles which use neuro-fuzzy systems have appeared. Most of them control the vibration passenger's vehicle suspension, improving the comfort in the vehicle body [12]. In other applications neuro-fuzzy velocity tracking control with reinforcement learning has been implemented in a real prototype, but only tested in special condition, not in real tracks (on a drive roller)[12], and using inconsistent data in the neural network training.

The AUTOPIA group, where this work was developed, is part of the Institute of Industrial Automation of the Spanish National Research Council (IAI-CSIC). From the beginning, its main goal has been to develop control strategies for mass-produced vehicles [14]. The main purpose of this work is to improve previous fuzzy controllers developed in the group [15], taking the experience of different expert drivers and considering the comfort and efficient use of actuators. For this purpose, a neuro-fuzzy system is considered, specifically an Adaptive Network Based Fuzzy Inference System 
(ANFIS), where the previous rule base and the experience of the expert drivers have been used as start point.

These experts are drivers that know the feature of the vehicle and the tested tracks, which has some slopes and curves that have an effect on vehicle dynamic. To keep the reference speed in these conditions is difficult for human drivers.

This paper is organized as follows. In Section II, we describe the system, explaining the longitudinal actuators. An overview of the previous longitudinal control is presented in Section III. The real time experiments carried out with the neuro-fuzzy controller and a comparative between both controllers are described in section IV. Finally some remarks and conclusions are presented in Section V.

\section{Autonomous Vehicle. ExPerimental Platform}

Researching in autonomous vehicles field has special interest because they can help to reduce traffic accidents and to improve the comfort in the driving. A comfortable driving can be achieved with an efficient use of the longitudinal actuators. Although the lateral actions may have an effect on the longitudinal dynamic, in this work only throttle and brake will be considered as output control variables.

The test vehicle used in this work is propelled by a gasoline motor. Its steering assistance is electric. The throttle pedal generates two signals: one of them from 0 to 5 volts, and the range of the other one is half of it. That is used as control action. The CAN bus of the vehicle provides the control signal form the speed and steering wheel angle given by the sensors.

In order to automate the throttle, two signals generated by a digital to analogue converter embedded in the computer feed the motor control.

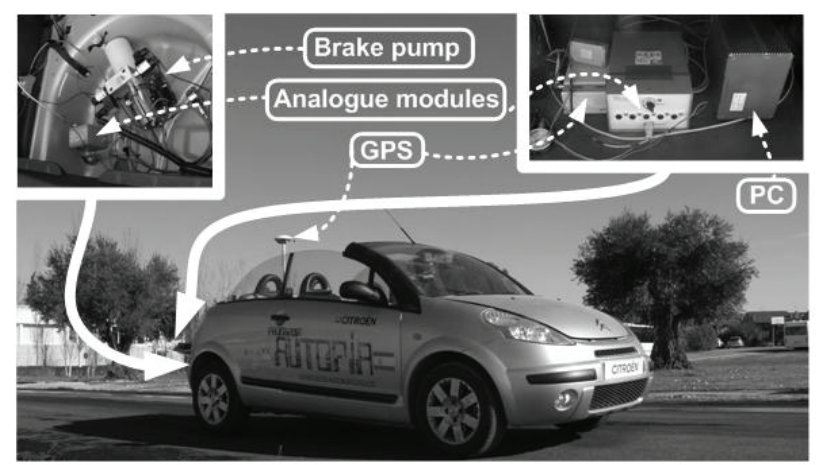

Fig. 1. Test vehicle and the actuators

The steering is controlled as follows. The wires lines leading to the assistance electric motor are cut and replaced by a line taken directly from the battery. That is, a modulated width pulse is codified according to the analogue signal controlled by the computer.

An additional braking system has been added without disabling the original one. It is formed by a pump whose pressure is controlled by an analogue signal, also generated by the computer. Fig. 1 shows the actuated vehicle.
The control is based in a RTK -DGPS which provides centimetric accuracy. In order to follow a track, the path is followed manually and the sequence of points is read from the GPS. A map is then generated by a sequence of points with a speed value attached, and manually added to each line. Later, when following the track in automatic mode, the GPS readings allow to determine two variables: the segment of the track where the car is, and the lateral distance to the desired point.

The segment of the map is used to control the speed, and the lateral displacement is used to control the steering. Fig. 2 shows a diagram of the control architecture implemented in the test vehicle.

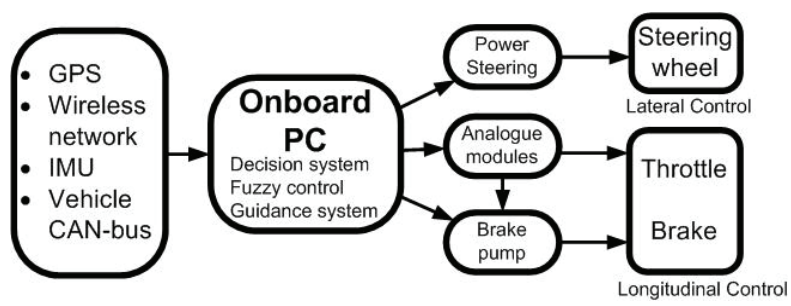

Fig. 2. Vehicle control scheme.

The control of the autonomous vehicle is divided into three main phases: perception, decision, and action. The first phase is responsible of receiving information from the environment (position, speed, information from others vehicles and infrastructure), through the different sensors and communication system. The decision phase is responsible for evaluating the conditions obtained in the perception phase, and sends the target to the action phase.

\section{FUZZY LOGIC LONGITUdinal CONTROL}

The decision phase of the control of our autonomous vehicle is divided into two tasks: to determinate the conditions of the environment and to send the control references to the throttle, brake and the steering wheel. This work is only focused on the longitudinal control.

The autonomous vehicle control system is based on fuzzy logic. An experimental fuzzy coprocessor called ORBEX (Spanish acronym of Experimental Fuzzy Coprocessor) has been developed [14]. It is an inference motor that uses natural-language-based inputs. It allows variables to be defined and combined in rules of the form: "IF...THEN...". In the inference method, it uses Mamdani-type [16], and singleton-type membership functions to codify the output variables, as Tagaki and Sugeno suggested [6]. The goal of the fuzzy logic is to use the expert knowledge to emulate the behaviour of human drivers.

The starting point of this work can be found in previous works [15][17], where the control of both actuators on an electric van and on the gasoline vehicle used here was implemented with promising results. Details on the membership functions, rule base description, singleton outputs can be found in [17]. This controller defines two fuzzy outputs for each actuator, the throttle and brake. Also, a switch in the output of the control makes that both actuators cannot work at the same time.

The input variables of the longitudinal control are: 
error_speed and acceleration. The first is the different between the actual speed and the target speed of the vehicle $(\mathrm{km} / \mathrm{h})$. The second is the longitudinal acceleration or the variation of the vehicle speed at each time instant. The same membership functions are used to describe both linguistic variables.

Fig. 3 shows the behaviour of the vehicle with this fuzzy controller [17]. A segment of a real circuit at our facilities was selected for the experiments. Some slope (less than 4 degrees) and curves of the tracks are considered as external perturbations, affecting the longitudinal dynamics of the vehicle.

Two target speeds were defined for these experiments, 10 and $20 \mathrm{~km} / \mathrm{h}$. The upper part of Fig. 3 shows the target and actual speed of the route. At around 40 and 70 seconds, the vehicle takes two slopes. In these situations, the vehicle loses some power and moves slightly from reference.
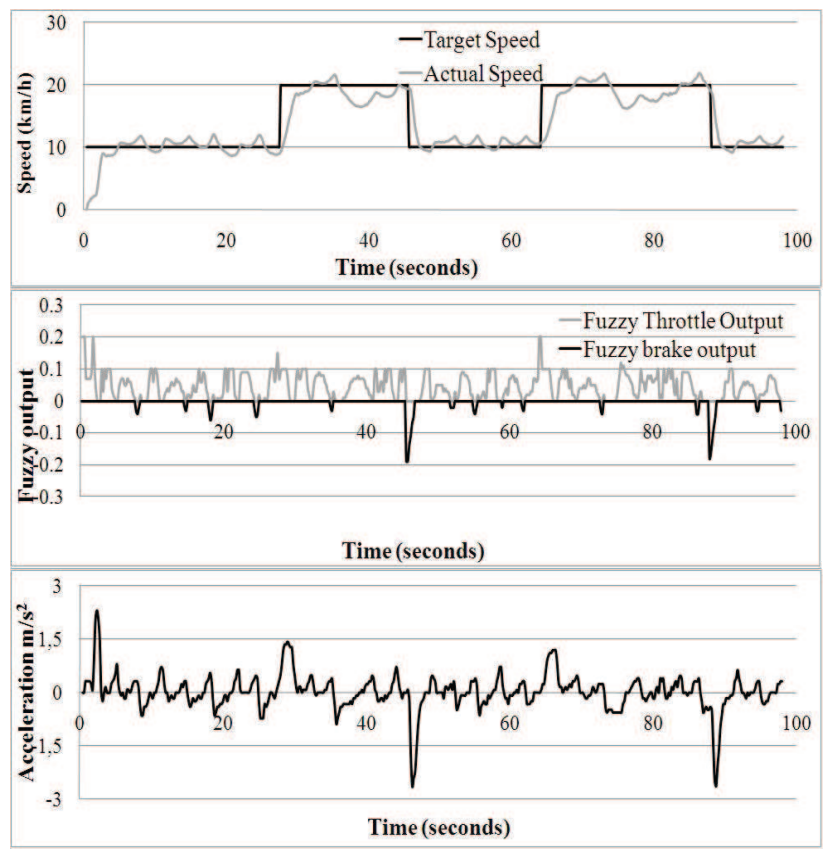

Fig. 3. Longitudinal fuzzy control: Vehicle speeds, Fuzzy outputs, Longitudinal acceleration.

The fuzzy outputs, throttle and brake, are shown in the middle of Fig. 3. In the lower part of the same figure, the acceleration is presented. In this study, the acceleration has two roles: it is an input of the fuzzy control and it is also the most important parameter to measure the comfort when driving.

The implemented fuzzy system has many advantages: low error, fast response, and robustness [18]. However, the system can be improved by considering the comfort and efficiency use of the actuators. The aim of this work is then to improve the system response (safety and comfort) taking advantage of the experience of different expert drivers to enhance the controller. For this purpose a neuro-fuzzy system has been implemented.

\section{LONGITUdinAL NEURO-FuZZY CONTROL}

The fusion of Artificial Neural Networks and Fuzzy Inference Systems has attracted growing interest among researchers in various fields of science and engineering because of the increasing necessity of developing adaptive intelligent systems to solve real world problems. Neural networks learn by adjusting the weight of the connections between the nodes (learning ability). Moreover, fuzzy inference systems provide an efficient environment or computing framework based on the concepts of fuzzy set theory, fuzzy if-then rules, and fuzzy reasoning. The advantages of combining neural networks and fuzzy inference systems are clearly presented in [8-13].

The Adaptive-Network-Based Fuzzy Inference System (ANFIS) was one of the first neuro-fuzzy systems developed [8]. Its principle is based on extracting fuzzy rules at each level of a neural network. Once the rules have been obtained, they provide the necessary information on the overall behaviour of the process.

ANFIS implements the Takagi-Sugeno model for the structure of the fuzzy system's if-then rules. The ANFIS architecture has five layers, as shown in Fig. 4. The nodes represented by squares have adjustable parameters, whereas the nodes represented by circles are fixed ones.

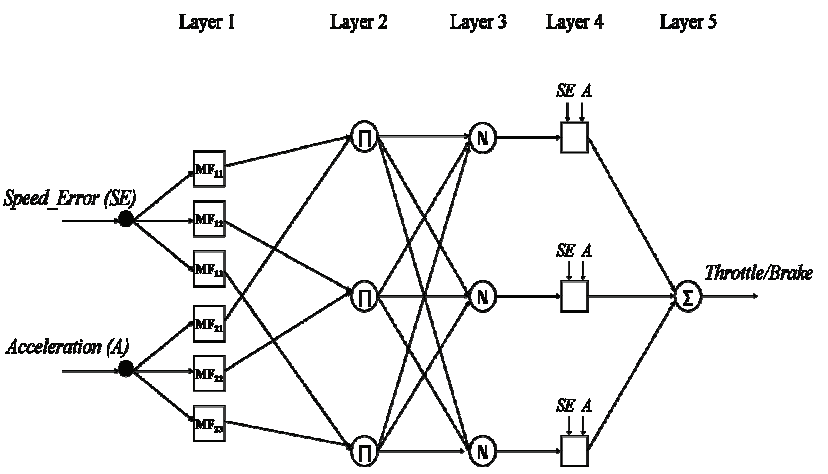

Fig. 4. ANFIS architecture of the system

The ANFIS system used in this work is built upon the fuzzy controller shown in [17]. Therefore the system has two inputs (Speed_Error and Acceleration) and one output (Throttle/Brake). Each input has three membership functions, leading to 9 rules. The output of the neurofuzzy system is in the range $[-1,1]$, where the interval [$1,0)$ corresponds to the brake and the range $(0,1]$ corresponds to the throttle.

The fuzzy controller has been proved to present a correct performance. However, in certain situations it has been found that a skilled driver results in a softer driving, that is, safer and more comfortable. For this reason ANFIS is used to provide the expert operator's knowledge to the system of rules already defined.

The error speed and the acceleration values were recorded, as well as the value of the accelerator and brake on a tour taken an expert driver. Three expert drivers followed the same track that was presented in section III. Figure 5 shows the response of the system for the three experts.

Due to the physical conditions of the tracks, the experts had some difficulties trying to keep the exact speed. All of them considered the reference speed like the maximum limit, and they try to use only the throttle and not the brake. 


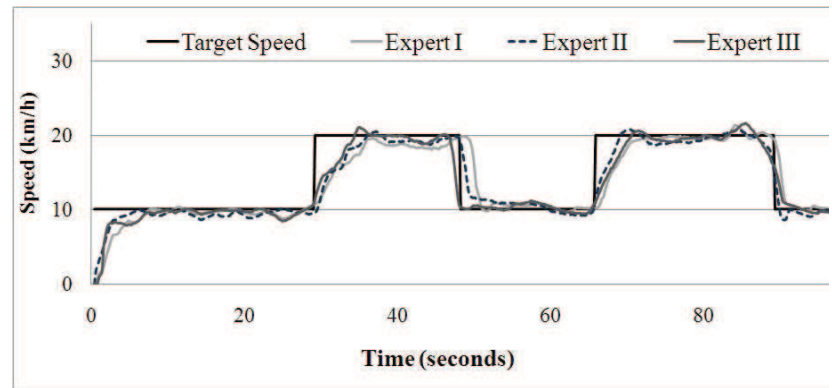

Fig. 5. Experiments by expert drivers.

The parameters chosen for training the ANFIS system and its structure are as follows (Table I):

TABLE I

ANFIS SYSTEM CONFIGURATION

\begin{tabular}{|c|c|}
\hline Algorithm & ANFIS \\
\hline System & $\begin{array}{c}\text { Two-inputs/single- } \\
\text { output }\end{array}$ \\
\hline $\begin{array}{l}\text { Membership functions } \\
\text { type }\end{array}$ & Trapezoidal \\
\hline $\begin{array}{l}\text { Number of membership } \\
\text { functions }\end{array}$ & 3 \\
\hline Inference system & $\begin{array}{l}\text { Takagi-Sugeno } \\
\text { (constant) }\end{array}$ \\
\hline Number of rules & 9 \\
\hline Iterations & 500 \\
\hline Learning rate & 0.001 \\
\hline Training algorithm & Back propagation \\
\hline Training data set & $\begin{array}{l}510 \text { samples } \\
\text { (1 experiment) }\end{array}$ \\
\hline Validation data set & $\begin{array}{c}987 \text { samples } \\
\text { (2 experiments) }\end{array}$ \\
\hline
\end{tabular}

The rule base of the longitudinal control generated by the neuro-fuzzy system is described by the following rules:

IF Speed error Negative AND Acceleration Negative THEN Output a05

IF Speed_error Negative AND Acceleration Positive THEN Output a02

IF Speed_error Negative AND Acceleration Null THEN Output a03

IF Speed_error Positive AND Acceleration Negative

THEN Output a06

IF Speed error Positive AND Acceleration Positive

THEN Output a07

IF Speed_error Positive AND Acceleration Null THEN

Output a09

IF Speed_error Null AND Acceleration Negative THEN Output a01

IF Speed_error Null AND Acceleration Positive THEN

Output a04

IF Speed_error Null AND Acceleration Null THEN

Output a08 II:

The values of the singleton outputs are listed in Table

TABLE II

\begin{tabular}{|c|c|}
\hline \multicolumn{2}{|c|}{ OUTPUT VALUES OF THE NEURO-FUZZY } \\
\hline $\mathrm{a} 01$ & 0.005979 \\
\hline $\mathrm{a} 02$ & 0.08839 \\
\hline $\mathrm{a} 03$ & 0.1901 \\
\hline $\mathrm{a} 04$ & 0.01084 \\
\hline $\mathrm{a} 05$ & 0.2245 \\
\hline $\mathrm{a} 06$ & -0.101 \\
\hline $\mathrm{a} 07$ & -0.02014 \\
\hline $\mathrm{a} 08$ & 0.09938 \\
\hline a09 & -0.2186 \\
\hline
\end{tabular}

\section{REAL TIME EXPERIMENTS AND RESUltS}

The real time experiments show the behaviour of the proposed neuro-fuzzy controller working in the autonomous vehicle. They were carried out in the same condition of the experiments of Section III (with a fuzzy controller) and IV (expert drivers). That is, vehicle speeds between $10 \mathrm{~km} / \mathrm{h}$ and $20 \mathrm{~km} / \mathrm{h}$ and the same track.

Fig. 6 shows a comparison between the membership function of the inputs and the singleton output for the fuzzy and the neuro-fuzzy controllers. Both membership functions are triangular or trapezoidal. Black lines represent the functions generated by ANFIS, and gray lines correspond to the fuzzy one. As it is possible to see, acceleration is the variable that has most changed, from a trapezoidal to triangular shape.
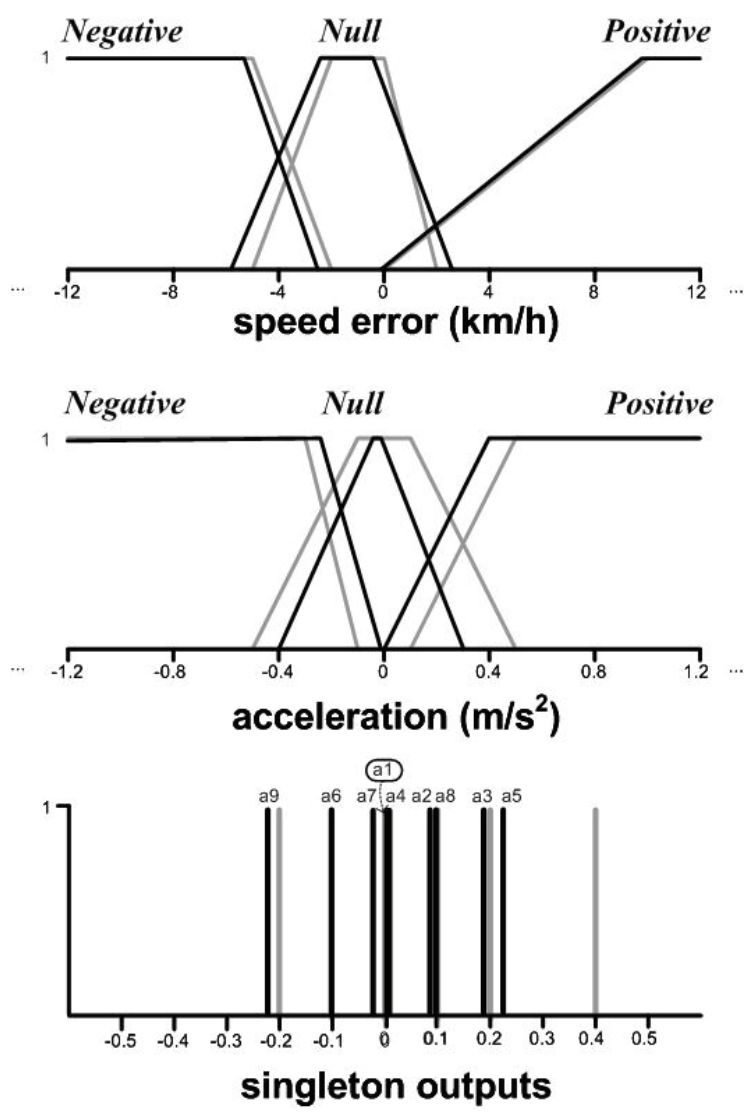

Fig. 6. Membership functions and singleton outputs generated by the neuro-fuzzy controller. 
The first experiment was carried out on a track with curves around 90 degrees and two slopes, as in the previous experiments. The total distance is 400 metres long.

The upper part of Fig. 7 shows the reference and the actual speed obtained by the neuro-fuzzy controller. It is possible to see as the system has leant to the expert drivers (Fig. 5), as it maintains the speed close to the lower limit of the speed. There is not overshoot on the response. It works as a cautious drive would do.

When the vehicle is at around 50 and 80 seconds, it takes two slopes. The average of the speed in this experiment is lower than in the previous values shown in Fig. 3, that is, $13.75 \mathrm{~km} / \mathrm{h}$ for the fuzzy control and 12.52 $\mathrm{km} / \mathrm{h}$ for the neuro-fuzzy one. This may be caused because the vehicle never surpasses the reference.

The output of new controller is shown in the middle of Fig. 7. The gray line corresponds to the fuzzy throttle output and the black one is fuzzy brake output.

This new controller presents a better behaviour in terms of efficiency, since the motor consumes less fuel. The throttle is just around 0.2 when the reference speed changes (at the beginning of the experiment, and at around 30 and 70 seconds). In the rest of the experiment the output values are less that 0.05 in all the cases.

The average of the fuzzy throttle output is 0.0454 for the previous controller (Fig. 3), while for the new neurofuzzy controller is 0.0245 . This means a reduction of $46.1 \%$ in the use of the motor acceleration.

The fuzzy brake output also presents better results as the brake is just used when the reference speed is reduced.

The behaviour is therefore closer to a human driver, who only uses the brake to stop or to cut down the speed in special situations, and not for keeping the speed (Cruise Control). Comparing both controllers, the reduction is about the $55.7 \%$ in terms of brake efficiency.

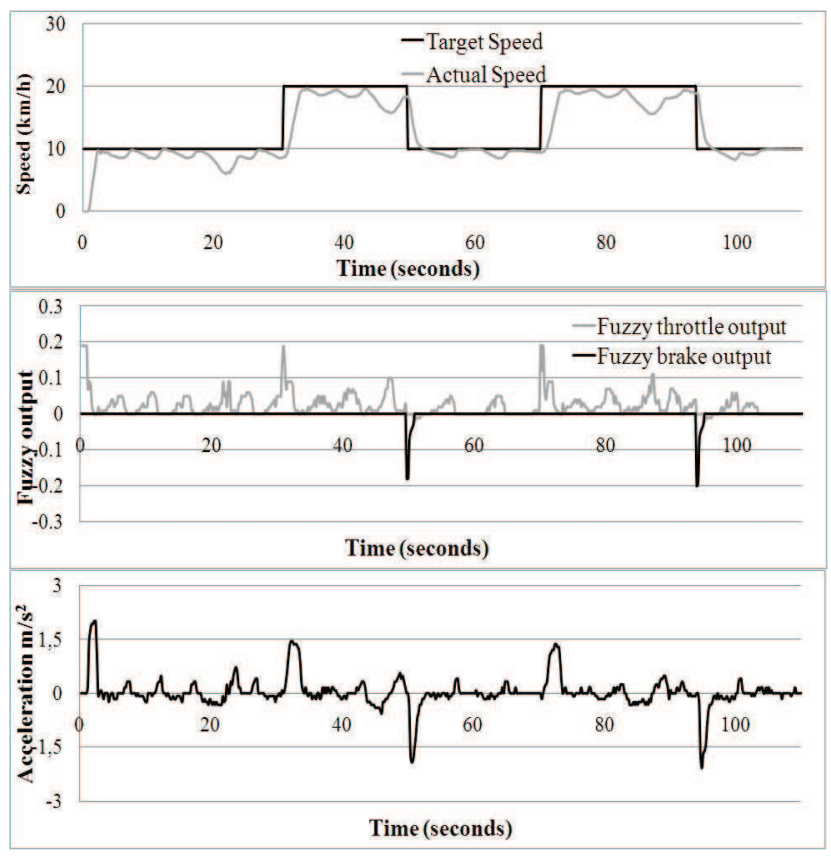

Fig. 7. Longitudinal neuro-fuzzy control: Vehicle speeds, Fuzzy outputs, Longitudinal acceleration.
In the middle of Fig. 3 we could see how the brake was applied to keep the reference at several instants. However, in Fig. 7, the brake is just used at around 50 and 95 seconds, and it is never used during the rest of the experiment because is unnecessary (as expected when an expert is driving).

Consequently, the longitudinal acceleration in the vehicle is reduced, as shown in the lower part of Fig. 7. The average of the acceleration has been reduced from $0.0498 \mathrm{~m} / \mathrm{s}^{2}$ to $0.0267 \mathrm{~m} / \mathrm{s}^{2}$. This means a $46.43 \%$ less, and therefore a significant improvement in the comfort of the driving.

\section{CONCLUSIONS}

This work presents the real time implementation of a neuro-fuzzy controller that has been applied to intelligent transportation systems. The purpose of this controller is to improve the response of a vehicle propelled by a gasoline motor. This neuro-fuzzy system enhances the performance of a previous fuzzy controller by incorporating the experience of expert drivers. The new fuzzy controller was tuned by considering the experiments carried out by three expert drivers. Although the knowledge base is still small, the neuro-fuzzy system was able to learn from these data, giving satisfactory results.

The throttle and brake are used in a more efficiently way when this neuro-fuzzy controller is applied, like a good driver would do. The brake is only used when the vehicle must reduce the speed or stops, and the throttle is just used to keep the reference speed and to accelerate. These results have been shown by real time experiments on an autonomous gasoline vehicle.

Neuro-fuzzy systems have many applications in ITS area. Designing, tuning and implementation of the lateral control will be considered for future works. Moreover, neuro-fuzzy techniques will be used to model the behaviour of the vehicle, and we think that this will help us to improve the current controllers in the autonomous driving.

The longitudinal control can also be improved if other variables are taking into account in the control loop. In future works, a multivariable system, considering longitudinal and transversal variables, may be designed. Moreover, the climate factor will also be considered.

\section{REFERENCES}

[1] J. P. Laumond, ed., "Robot Motion Planning and Control", vol. 229. New York: Springer-Verlag, 1998.

[2] S. E. Shladover, "Review of the state od development of advanced vehicle control systems (avcs)," Vehicle System Dynamics, vol. 24, pp. 551-595, 1995.

[3] S. Zhao, Y. Li, L. Zheng, and S. Lu, "Vehicle lateral stability control based on sliding mode control," in Proc. IEEE International Conference on Automation and Logistics, 18-21 Aug. 2007, pp. 638-642.

[4] M. Sugeno and M. Nishida, "Fuzzy control of model car," Fuzzy Sets and Systems. 16, 103-113,1985.

[5] L. A. Zadeh, "Fuzzy sets," Info. Contr., vol. 8, pp. 338-353, 1965.T. Takagi and M. Sugeno, "Fuzzy identification of systems and its applications to modelling and control," IEEE Trans. Syst., Man, Cybern., 15(1), 116-132, 1985.

[6] T. Takagi and M. Sugeno, "Fuzzy identification of systems and its applications to modeling and control," IEEE Trans. Syst., Man Cybern., vol. SMC-15, pp. 116-132, Jan./Feb. 1985. 
[7] M. A. Denai, F. Palis, and A. Zeghbib, "Modeling and control of non-linear systems using soft computing techniques," Applied Soft Computing Journal, vol. 7, pp. 728-738, 2007.

[8] J.-S. R. Jang, "ANFIS: adaptive-network-based fuzzy inference system," IEEE Transactions on Systems, Man and Cybernetics, vol. 23, pp. 665-685, 1993.

[9] R. Babuska and H. Verbruggen, "Neuro-fuzzy methods for nonlinear system identification," Annual Reviews in Control, vol. 27, pp. 73-85, 2003.

[10] H. Chen, "Fuel Injection Control and Simulation of EFI Engine Based on ANFIS," in Intelligent Computation Technology and Automation (ICICTA), 2008 International Conference on, 2008, pp. 191-194.

[11] C. Quek, M. Pasquier, B. Lim, "A novel self-organizing fuzzy rulebased system for modelling traffic flow behaviour", Expert Systems with applications, vol 36, pp. 167-178, 2009.

[12] R. Vatankhah, M. Rahaeifard, A. Alasty, "Vibration control of vehicle suspension system using adaptive critic-based neurofuzzy controller", 6th International Symposium on Mechatronics and its Applications, ISMA 2009.
[13] J. Xue, W. Zhang and Z. Gong, "Neurofuzzy velocity tracking control with reinforcement learning", The ninth International Conference on electronic measurement \& instruments, ICEMI 2009.

[14] R. Garcia, T. De Pedro. "First Application of the ORBEX Coprocessor: Control of Unmanned Vehicles". EUSFLATESTYLF Joint Conference. Mathware and Soft Computing, n. 7, vo12-3, 2000, pp. 265-273, 1999.

[15] J.E. Naranjo "ACC+Stop\&Go Maneuvers With Throttle and Brake Fuzzy Control" IEEE Transactions On Intelligent Transportation Systems, VOL. 7, NO. 2, june,2006.

[16] E. H. Mamdani, "Applications of fuzzy algorithms for simple dynamic plant," Proc. IEEE, vol. 62, no. 12, pp. 1585-1588, Dec. 1974.

[17] E. Onieva, V. Milanés, C. González, T. de Pedro, J. Pérez, J. Alonso "Throttle and Brake Pedals Automation for Populated Areas", ROBOTICA, 2009 (in Press).

[18] V. Milanés, J. Pérez, E. Onieva and C. González “Controller for Urban Intersections Based on Wireless Communications and Fuzzy Logic" IEEE Transactions On Intelligent Transportation Systems, Vol. 11, no. 1, pp. 243-248, March 2010. 